\title{
Prey selection and capture strategies of the benthic hydroid Eudendrium racemosum
}

\author{
Manuel Barangé \\ Institut de Ciéncies del Mar, Passeig Nacional s/n. 08003 Barcelona, Spain \\ and
}

Departament d'Ecologia, Facultat de Biologia, Universitat de Barcelona, Diagonal 645. 08028 Barcelona, Spain

\begin{abstract}
This paper examines prey capture strategies of a passive benthic suspension feeder, the hydroid Eudendrium racemosum (Cavolini, 1785), in relation to its biometry, size structure of particles captured, and size structure of potential prey. Results demonstrate: (1) polyp size is relatively fixed and constant for all zooids of the colony; (2) size structure of prey items is similar to that of the natural zooplankton population; (3) prey selection cannot be demonstrated for most prey groups. These points favor a model of capture strategy, here referred to as Multidirectional Feeding Strategy; it conceptualizes prey capture as the result of the interaction of direct interception, inertial impactation, and gravitational deposition. This model may be extrapolated to other colonial benthic suspension feeders, the relative importance of the different mechanisms depending upon organismic size and habitat conditions. Our results suggest that past models, proposed on the basis of laboratory experiments, oversimplify the process of prey capture because they fail to consider adequately all the mechanisms involved.
\end{abstract}

\section{INTRODUCTION}

Because of the constraints imposed by their sessile habit, the biomechanical design of suspension feeders has often been emphasized in studies of their feeding behaviour (Wainwright \& Koehl 1976, Rubenstein \& Koehl 1977, Sebens 1982, Koehl 1984, LaBarbera 1984). Rubenstein \& Koehl (1977) postulated that sieving should be less important for passive suspension feeders than 'aerosol filtration', and that the most common 'aerosol' mechanism used by these animals should be the direct interception of particles by one of the filtering fibers. Because prey capture of passive suspension feeders largely relies on externally generated water motions, these organisms are often located in areas exposed to moderate or high water movement. Despite the important influence of biomechanical constraints, colonial zooids are expected to achieve fixed size (Ryland \& Warner 1986), and to be adapted to the fairly predictable size structure of zooplankton populations (Sebens 1982).

We examine the feeding strategies under in situ conditions of colonial benthic suspension feeders, using as model organism the hydroid Eudendrium racemosum; it occurs in our study area on sites between 0 and $10 \mathrm{~m}$ depth exposed to turbulent flow. Our goal was to test whether the high intake rate characteristic of this species (Barangé \& Gili in press) relies on a single feeding mechanism or results, instead, from interaction of different mechanisms. Integration of a variety of feeding mechanisms (hereafter referred to as Multidirectional Feeding Strategy, or MFS) will allow E. racemosum to expand the range of prey size and habitat (i.e. benthic, epibenthic, and planktonic). This mechanism requires that polyp size be adapted to the size structure of potential prey. Our hypothesis implies that: (1) Polyp size should be relatively fixed, allowing a functional conception of zooids as modules. An irregular size distribution of the zooids would imply differences in their feeding strategy. (2) The size structure of prey particles captured should be similar to the size structure of the potential prey (zooplankton in the environment). (3) Feeding should be truly passive with no bias towards favored capture of any particular group of prey in relation to their relative abundance in the environment. (4) Because of the wide range of prey size and habit (sessile, motile, benthic, epibenthic, planktonic, etc.) available in the environment, the predators are likely to combine different mechanisms of prey capture. This is not contrary to the 
hypothesis of Rubenstein \& Koehl (1977) which postulates that prey capture should rely on direct contact with single tentacles due to biomechanical constraints of sieving but extends it due to the high size range of prey particles captured, caused by the combination of the morphological structure of colonial organisms and their capture mechanisms. In this way we consider that the capture of prey particles, both larger and smaller than the distance between fibers (i.e. tentacles), can be assumed to be evidence for the existence of alternative capture mechanisms.

\section{MATERIAL AND METHODS}

Eudendrium racemosum develops extensive populations in shallow submarine substrates around the Medes islands (NE Spain). This hydroid forms arborescent colonies up to $12 \mathrm{~cm}$ high, each comprising an average of over 250 polyps. Prey size and nature were assessed from healthy colonies collected in three $24 \mathrm{~h}$ sampling periods (September 1985, July 1986, September 1986) from the same population (12 $\mathrm{m}$ water depth) by SCUBA divers. The potential prey population was sampled simultaneously to the polyp sampling with a net ( $53 \mathrm{~cm}$ mouth diameter, $350 \mu \mathrm{m}$ mesh-size) towed from bottom to surface $(12 \mathrm{~m})$ parallel and as close as possible (ca 50 to $100 \mathrm{~cm}$ ) to the hydroid population. Coelenteric contents of the zooids forming the colony were removed and identified to the same taxonomic level as the organisms captured with the net tows (see Barangé \& Gili 1988 for further details).

The selectivity index for the different prey items (E) was calculated from the algorithm (Ivlev 1961) $\mathrm{E}=(r-p)$ / $(r+p)$, where $r=$ frequency of a given prey item in the diet $_{i} p=$ its frequency in the natural prey population. We also calculated an alternative index based on the 'log of odd' ratio (LOR, Gabriel 1978), that has been applied to a coelenterate population (Larson 1987).

The data necessary to test the hypothesized constancy of polyp size were obtained through measure- ments of healthy colonies selected on an ad hoc basis and collected in August 1987. Some of these colonies were anesthetized immediately after collection to avoid polyp retraction by enclosing them in a closed jar for $24 \mathrm{~h}$, and subsequently fixed with $4 \%$ formalin. We measured the size (length and width) of polyps, and the length of tentacles, and we tallied the number of tentacles for every polyp of one of these colonies $11 \mathrm{~cm}$ high, and having 41 newly-born polyps and 12 male gonophores). All other colonies were preserved in $10 \%$ formalin immediately after collection, and the coelenteron contents of their polyps examined as previously described. Simultaneous to the hydroid collection, a plankton net ( $30 \mathrm{~cm}$ mouth diameter, $60 \mu \mathrm{m}$ mesh-size) was towed by a diver parallel to the substratum at a distance of approximately $20 \mathrm{~cm}$ from the rock wall, thus allowing the comparison between the size structure of the prey and that of the planktonic population.

\section{RESULTS}

\section{Eudendrium racemosum biometry}

Average ( \pm standard deviation) of the 4 biometrical variables studied here are shown in Table 1. The kurtosis coefficients reflect the spread of the data around the mean; the negative kurtosis for the number of tentacles probably reflects the narrow range encountered ( 20 to 36 tentacles polyp ${ }^{-1}$ ). The coefficients of variation ( $\mathrm{SD} / \mathrm{X}$ ) of the data are between 0.24 and 0.11 for every parameter. These small variations from the means support Ryland \& Warner's (1986) contention that polyp size and number, as well as tentacle size, should be relatively constant.

\section{Prey size structure and plankton size structure}

Prey size structure (log geometric mean, in $\mathrm{mm}=$ $-0.48 \pm 0.22$ standard deviation) and the zooplankton

Table 1 Eudendrium racenosum. Average (and standard deviation, SD), and kurtosis and skewness coefficients for polyp length and width, and tentacle length and number of the population studied. Also provided are allometrical relation (i.e linear regression equations and correlations coefficient, $r$ ) between these variables. $n=262$ polyps. All correlation coefficients are significant at $p=0.001$ level

\begin{tabular}{|lcccc}
\hline & Average & SD & K coeff. & S coeff. \\
\hline Polyp length (L) & 0.414 & 0.10 & 0.74 & 0.56 \\
Polyp width (W) & 0.437 & 0.08 & 3.16 & 1.18 \\
Tentacle length (TL) & 0.710 & 0.17 & -0.003 & 0.13 \\
Tentacle rumber (TN) & 27.70 & 3.01 & -0.41 & 0.24 \\
$\mathrm{~L}=0.079+0.76 \mathrm{~W}$ & $\mathrm{r}=0.64$ & $\mathrm{~L}=0.176+0.33 \mathrm{TL}$ & $\mathrm{r}=0.59$ \\
$\mathrm{~L}=0.127+0.01$ TN & $\mathrm{r}=0.32$ & $\mathrm{~W}=0.269+0.23 \mathrm{TL}$ & $\mathrm{r}=0.50$ \\
$\mathrm{~W}=0.239+0.007$ TN & $\mathrm{r}=0.26$ & $\mathrm{TL}=0.367+0.01 \mathrm{TN}$ & $\mathrm{r}=0.22$ \\
\hline
\end{tabular}


Fig. 1. Size structure of prey and zooplanktonic populations
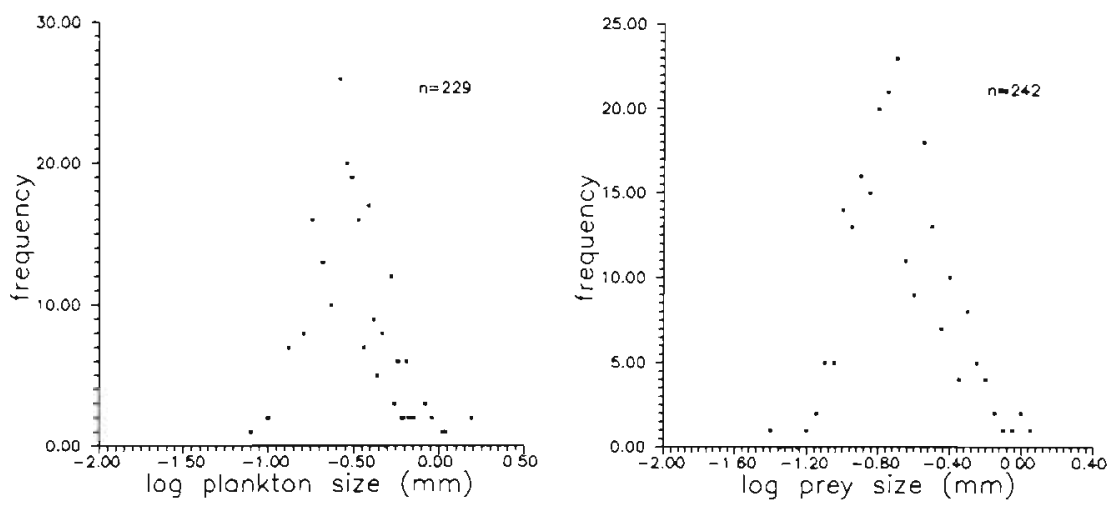

size structure (log geometric mean $=-0.68 \pm 0.25)$ are not statistically different ( $t$-test, $p<0.001$, Fig. 1 ). The size ranges of both distributions are also similar, with a greater variability in the lower size range. We consider that this difference in the lower size range is attributable to measuring error, because the smaller magnification $(15$ to $20 \times$ ) used for the examination of zooplankton compared to that used to examine prey organism $(40$ and $100 \times$ ) should enable the observation of zooplankton organisms larger than the smaller prey organism.

\section{Prey selectivity}

The most abundant prey items were divided into 14 different groups comprising more than $95 \%$ of the prey and $90 \%$ of the plankton, and the degree of selectivity for each of them was then assessed using the Ivlev (E) and Gabriel (LOR) selectivity indexes. The high degree of between-sample variability in the selectivity indexes (Table 2) is a consequence of the wide diversity of organisms captured by this carnivorous organism combined with the small capture rates for any prey group that determines that small variations in the number of prey items within a group $( \pm 1)$ have a considerable impact on the selectivity index. Examination of the selectivity indexes (Fig. 2) reveals a tendency towards positive selectivity of benthic organisms (e.g. nematodes, turbellarians), which are obviously rare in the plankton community. On the other hand, the negative selection indexes observed for amphipods and cladocerans may be the result of their large size (Table 3). Particularly revealing are the strongly positive selectivity for nauplius and cypris larvae.

The distribution of the selectivity indexes among prey groups points to mechanical constraints (i.e. size,

Table 2. Percent contribution (by number) of different organismal classes to the prey and planktonic populations, and degree of selectivity (Gabriel's index, LOR; and Ivlev's index, E) for each of these organismal groups (values $>0$ represent positive, and values $<0$ negative selection

\begin{tabular}{|c|c|c|c|c|c|c|c|c|c|c|c|c|}
\hline \multirow[b]{2}{*}{ Prey items } & \multicolumn{4}{|c|}{ September 1985} & \multicolumn{4}{|c|}{ July 1986} & \multicolumn{4}{|c|}{ September 1986} \\
\hline & $\begin{array}{l}\% \text { in } \\
\text { diet }\end{array}$ & $\begin{array}{c}\% \text { in } \\
\text { envir }\end{array}$ & LOR & E & $\begin{array}{l}\% \text { in } \\
\text { diet }\end{array}$ & $\begin{array}{l}\% \text { in } \\
\text { envir. }\end{array}$ & LOR & E & $\begin{array}{l}\% \text { in } \\
\text { diet }\end{array}$ & $\begin{array}{l}\% \text { in } \\
\text { envir. }\end{array}$ & LOR & $\mathrm{E}$ \\
\hline Copepods & 28.84 & 39.90 & -0.15 & -0.16 & 42.4 & 40.8 & 0.01 & 0.02 & 44.74 & 79.88 & 0.43 & -0.28 \\
\hline Cladocerans & 0.36 & 0.31 & 0.01 & 0.075 & 0.39 & 46.32 & -4.6 & -0.98 & 1.26 & 3.22 & 0.40 & -0.44 \\
\hline Amphipods & 1.18 & 5.74 & -1.56 & -0.65 & 0.08 & 0.89 & -2.41 & -0.83 & 0.93 & 0.81 & 0.14 & -0.07 \\
\hline Gastropods & 0.25 & 4.59 & -2.81 & -0.89 & 7.09 & 1.12 & 1.78 & 0.73 & 8.29 & 0.37 & 3.02 & 0.91 \\
\hline Bivalves & 5.66 & 7.90 & -0.31 & -0.16 & 19.59 & 0.35 & 3.81 & 0.96 & 4.48 & 0.47 & 2.21 & 0.81 \\
\hline Polychaetes & 1.08 & 11.90 & -2.30 & -0.83 & 3.53 & 0.38 & 2.19 & 0.80 & 3.29 & 0.33 & 2.27 & 0.82 \\
\hline Nematodes & 14.83 & 5.48 & 0.89 & 0.46 & 1.18 & 0.07 & 2.81 & 0.89 & 6.82 & 2.25 & 1.06 & 0.50 \\
\hline Nauplii & 13.06 & 0.21 & 3.99 & 0.97 & 14.11 & 1.05 & 2.45 & 0.86 & 6.73 & 0.34 & 2.92 & 0.90 \\
\hline Cyprid larvae & 23.54 & 1.01 & 2.89 & 0.92 & 3.06 & 1.05 & 1.05 & 0.49 & 2.82 & 0.30 & 2.21 & 0.81 \\
\hline Other larvae & 1.93 & 5.21 & -0.96 & -0.46 & 1.07 & 2.13 & -0.68 & -0.33 & 3.81 & 3.73 & 0.02 & 0.01 \\
\hline Inv. eggs & 5.38 & 2.74 & 0.65 & 0.32 & 3.60 & 1.34 & 0.96 & 0.46 & 10.68 & 0.79 & 2.50 & 0.86 \\
\hline Siphonophores & - & - & - & - & 0.17 & 0.34 & -0.69 & -0.33 & 0.53 & 0.28 & 0.63 & 0.31 \\
\hline Turbellarians & 1.00 & 0.18 & 1.70 & 0.69 & 0.19 & 0.004 & 3.86 & 0.96 & - & - & - & - \\
\hline Foraminiferans & 0.75 & 5.03 & -1.89 & -0.74 & - & - & - & - & - & - & - & - \\
\hline Other & 2.14 & 9.71 & - & - & 3.57 & 4.10 & - & - & 4,20 & 6.78 & - & - \\
\hline Total items & 220 & 3520 & & & 606 & 19768 & & & 565 & 7640 & & \\
\hline
\end{tabular}



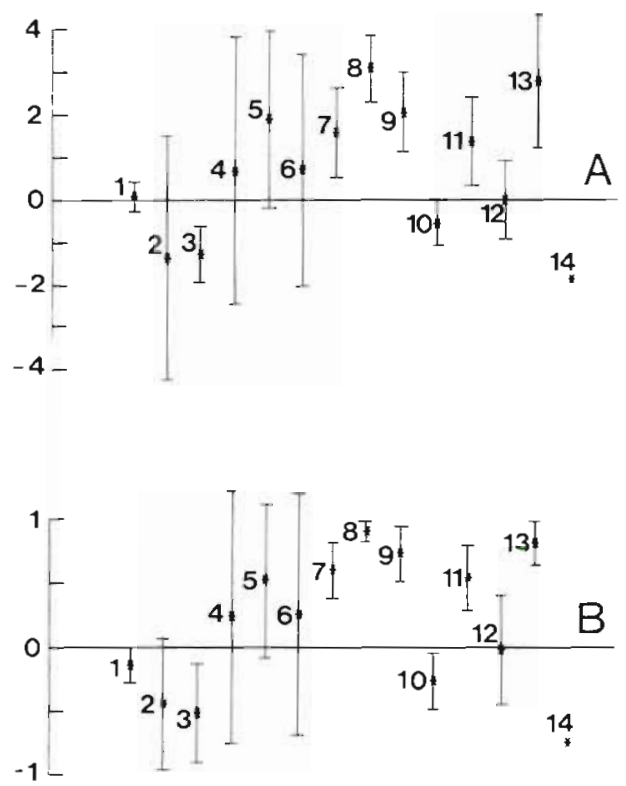

Fig. 2. Eudendrium racemosum. Selectivity values (mean \pm standard deviation for the three $24 \mathrm{~h}$ cycles) for each of the organismic classes. (A) Gabriel's index; (B) Ivlev's index: 1, copepods; 2, cladocerans; 3, amphipods; 4 , gastropods; 5 , bivalves; 6 , polychaetes; 7 , nematodes; 8 , nauplii; 9 , cyprids; 10, other larvae: 11 , invertebrate eggs; 12 , siphonophores; 13 , turbellarians; 14 , foraminiferans

Table 3. Average size (length, $\mu \mathrm{m}$ ) for the different classes of organisms captured by the studied population of Eudendrium racemosum. Data derived from the examination of coelenteric contents

\begin{tabular}{|lc|}
\hline & Average length (um) \\
\hline Nematodes & 475.5 \\
Turbellarians & 233 \\
Polychaetes & 544.2 \\
Gastropods & 185.5 \\
Bivalves & 173.5 \\
Copepods & 326.3 \\
Cladocerans & 600 \\
Amphipods & 1133 \\
Sponge larvae & 324 \\
Nauplius larvae & 127.6 \\
Cyprid larvae & 157.5 \\
Invertebrate larvae & 300 \\
Invertebrate egg & 168.3 \\
\hline
\end{tabular}

motility) as the most important factors influencing prey capture.

\section{Capture strategy}

Comparison of mean and range of prey size with distance between filtering elements (Fig. 3) suggests that prey capture cannot be based solely on prey inter-

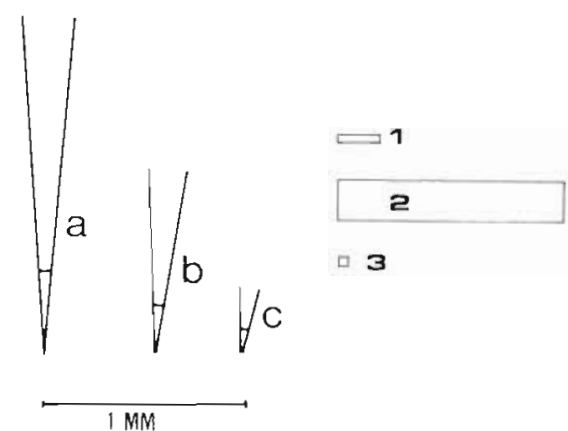

Fig. 3. Eudendrium racemosum. Schematic representation of distance between tentacles for large (a), medium (b), and small (c) polyps, compared to the length of medium (1), large (2), and small (3) prey particles. The filtering surface can be calculated as the arc of a circle with diameter equal to $(2 T L)+W$ The circle was divided by the minimum, medium, and maximum number of tentacles. (TL: tentacle length; $W$. polyp width)

ception after contact with one tentacle (contra Rubenstein \& Koehl 1977). Because a considerable fraction of the prey are larger than the distance between tentacles their capture should be explained by means of different mechanisms. First, we consider that tentacles could act as a barrier (tentacles working as a whole structure, not individually), thus capturing big particles. Second, very small particles (e.g. diatoms) were probably captured because of the continuous movement of the tentacles that results in sudden increases and decreases of the distance between the filtering elements. Third, particles in the middle part of the size spectra were captured by direct interception (planktonic organisms) or gravitational deposition (benthic organisms).

\section{DISCUSSION}

The biometrical characteristics of the population examined are similar to previously reported values for populations in this area (Gili 1986), although previous studies did not consider the size structure of the colonies. The size of polyps appears rather constant, with some small polyps probably corresponding to young growing polyps. The absence of significant differences between prey size of large and small polyps (data not shown) supports the postulated functional equivalence of the modules. Although data on number of tentacles are scarce in the Literature, it appears that Eudendrium racemosum has a high number of tentacles compared to previous quantifications (Ryland \& Warner 1986). The small coefficient of variation of the number of tentacles per polyp $(11 \%)$ indicates that this species can be considered functionally similar to a thecate 
hydroid (i.e. constant number of tentacles from birth to death) although belonging to the S. Cl. Athecata (number increasing with age).

Despite the sampling difficulties imposed by the highly diverse diet of these organisms (planktonic, benthic, epibenthic prey items), our results suggest that Eudendrium racemosum is a non-selective feeder, and that only mechanical constraints (i.e. prey size and motility) are responsible for its relatively low predation over cladocerans and amphipods. Because of the uncertainties involved in the comparison of the composition and size structure of the planktonic and prey populations, these conclusions should be regarded with caution. The use of a $350 \mu \mathrm{m}$ mesh-size net would reduce the number of small organisms, thus leading to a critical view of our selectivity indices. Nevertheless, the comparison of the size structure of the prey and of the zooplankton (sampled with a $60 \mu \mathrm{m}$ mesh-size net) leads to the same conclusion of the non-selective feeding of the species. The similarity between the size range of the prey and zooplankton indicates that prey size is adapted to the fairly predictable size of the zooplanktonic population, in agreement with the conclusion of Sebens (1982). The reason for this adaptation may be that the cost of increasing the capture of large organisms may not be energetically efficient. Final polyp size should reflect a balance among biomechanical constraints (Ryland \& Warner 1986), energetic constraints (Peters 1983), and predation and mortality (Sebens 1982), whereas the number and size of tentacles and cnidae appears to be determined primarily by prey size. In any case, it appears that polyp size (i.e. volume) is adapted only to the number of prey items captured. If all captured preys are consumed as they are encountered regardless of their size, E. racemosum can be envisioned as a truly passive suspension-feeder ('number maximizer' feeding strategy, Griffiths 1975).

Our results suggest that the notion that filtering and retention of particles larger than pore size are not likely to occur in passive suspension feeders is an oversimplification. Eudendrium racemosum captures prey items of sizes between 30 and $1300 \mu \mathrm{m}$. Most of the work on capture strategies has been performed under controlled conditions at small prey ranges (e.g. 30 to $360 \mu \mathrm{m}$, LaBarbera $1981 ; 5$ to $30 \mu \mathrm{m}$, Boyd 1976; $48 \mu \mathrm{m}$, Leversee 1976) thus reproducing only part of what happens in nature or with species with smaller natural prey size ranges (e.g. 256 to $345 \mu \mathrm{m}, 415$ to 1006 , Sebens \& Koehl 1984). It is important to note that although biomechanics is not the unique component governing prey capture (e.g. physiological control of nematocysts discharge should play an important role when deciding to continue or stop eating) it is the major factor controlling prey selectivity. Orientation of colonies growing from the sea bottom towards the open water allows to use as prey items benthic organisms (by gravitational deposition), animals living on the colonies (e.g. caprellid amphipods), as well as epibenthic and true planktonic organisms. Instead, we conclude that $E$. racemosum maximizes the number of particles captured by combining a series of feeding mechanisms and strategies (i.e. the erect position of the colony, the regular disposition of the zooids in the colony (data not shown), and the patchy distribution of the populations) that can be conceived as a multidirectional strategy (MFS) that should be also common to other passive suspension feeders that exploit different systems (planktonic, benthic, epibenthic)

Acknowledgements. I thank Dr J. M. Gili for stimulating discussions that contributed greatly to shaping the ideas reflected in this paper. Thanks are also due to Drs $M$. Zabala and $\mathrm{T}$. Riera for field assistance; Mrs. S. Agusti, for improving the English version of this article; and to 3 anonymous reviewers for critical reading of the manuscript.

\section{LITERATURE CITED}

Barangé, M., Gili, J. M. (1988). Feeding cycles and prey capture in the hydroid Eudendrium racemosum (Cavolini, 1785). J. exp. mar. Biol. Ecol. 115: 281-293

Boyd, C. M. (1976). Selection of particle sizes by filter-feeding copepods: a plea for reason. Limnol Oceanog. 21: 175-180

Gabriel, W. L. (1978). Statistics of selectivity. In: Lipovsky, S. J., Simensted, C. A. (eds.) Gutshop '78. Wash. Seattle (WA), Sea Grant Publ., p. 62-66

Gili, J. M. (1986). Estudio sistemático y faunistico de los cnidarios de la costa catalana. Ph. D. thesis, Univ. Barcelona

Griffiths, D. (1975). Prey availability and the food of predators Ecology 56: 1209-1214

Ivlev, V.S. (1961). Experimental ecology of the feeding of fishes. Yale Univ. Press, New Haven, Connecticut

Koehl, M. A. R. (1984). How do benthic organisms withstand moving water?. Am. Zool. 24: 57-70

LaBarbera, M. (1978). Particle capture by a Pacific brittle star Experimental test of the aerosol suspension feeding model. Science 201: 1147-1148

LaBarbera, M. (1984). Feeding currents and particle capture mechanisms in suspension feeding animals. Am. Zool. 24: $71-84$

Larson, R. J. (1987). Trophic ecology of planktonic gelatinous predators in Saanich Inlet. British Columbia: diets and prey selection. J. Plankton Res. 9: 811-820

Leversee, G. J. (1976). Flow and feeding in fan-shaped colonies of the gorgonian coral, Leptogorgia. Biol. Bull. mar, biol. Lab., Woods Hole 151: 344-356

Peters, R. H. (1983). The ecological implications of body size Cambridge Univ. Press, Cambridge

Rubenstein, D. I., Koehl, M. A. R. (1977). The mechanisms of filter feeding: some theoretical considerations. Am. Nat. 111: 981-994

Ryland, J. S., Warner, G. F. (1986). Growth and form in modular organisms: ideas on the size and arrangement of zooids. Phil. Trans. R. Soc. (B) 313: 53-76

Sebens, K. P. (1982). The limits to indeterminate growth: an optimal size model applied to passive suspension feeders. Ecology 63: 209-222 
Sebens, K. P., Koehl, M. A. R. (1984). Predation on zooplankton by the benthic anthozoans Alcyonium siderium and Metridium senile in the New England subtidal. Mar. Biol. 81: $255-271$
Wainwright, S. A., Koehl, M. A. R. (1976). The nature of flow and the reaction of benthic cnidaria to it. In: Mackie, G. O. (ed.) Coelenterate ecology and behaviour. Plenum Press, New York, p. 5-21.

This article was submitted to the editor; it was accepted for printing on May 10, 1988 